\title{
THE ASSESSMENT OF AND ADAPTATION TO DISEASE RISK IN LIOUCIOU TOWNSHIP, TAIWAN
}

\author{
Chung-Ling Ouyang*
}

National Taiwan Normal University, Department of Geography, Taiwan

\begin{abstract}
Liouciou Island, located off the south western coast of Taiwan, has 12,550 inhabitants of which high proportion are elderly and fisherman. The medical services are provided mainly by the local Public Health Clinic. Any emergencies or major medical treatment requires patients to be transferred to a regional hospital in Taiwan, which normally takes 40 minutes by the Ambulance boat. The aims of this paper are: 1) To examine the potential risk factors of disease based on the geography and medical services of Liouciou island; 2) To analyze the participants' perception of disease risk on the island at various spatial scales (individual, family, neighbor, island or nation); 3) To analyze the adjustment strategies towards disease risks used by the Liouciou island people. Questionnaires and in-depth interviews were used to gather the information. The results show that participants in Liouciou worried about the Ambulance boat not being able to sail in bad weather conditions. In addition, the young people complained about the local medical facilities and physician's skill while the elderly admitted their life was predetermined by God. The fishermen also reported that they were unable to follow up on their chronic disease. As a result, most of them ignored their health.
\end{abstract}

Key words: Remote district, Risk of local disease, Assessment, Adaptation.

Article Info: Manuscript Received: July 20, 2012; Accepted: October 29, 2012; Online: November 30, 2012.

\section{Introduction}

The different geographical and living conditions in each region on the island cause different features of local diseases. That is, local diseases can be seen as the outcome of the interaction between human and the natural environment. It follows that these local disease types are an important index when geographers examine local characteristics of a region. It is crucial to define the local disease type - especially defining the reasons for disease - because it will bring forth dissimilar results depending on the space scales you choose.

Moreover, the spread of disease has become much faster due to the development of time and space convergence. The various disease types have also tended to become more similar due to globalization. Even though the discrepancy between disease types is not as obvious as before, local residents' awareness of

\footnotetext{
* Correspondence address:

Address: 162 Ho-Ping East Road, Sec.1, Taipei (10610), Taiwan

Telephone: +886.2 .7734 .1678$

Email: t24013@ntnu.edu.tw
}

doi:10.5719/hgeo.2012.62.33 different disease risks from their living conditions or environmental risks have had an impact on their life and living quality.

Disease risk assessment focuses on the disease aspect of health risk assessment. For example people can do a forecast assessment through age, vocation or family medical history. Furthermore, the assessment of local disease risk aims at analyzing the disease risk assessment for a particular place where an individual is located. Thus local factors (including environmental and human) can be regarded as the primary assessment indicator. Because of these differences in local conditions bringing about different styles of local diseases, these conditions have also become one of the major issues of medical geography.

Hence, even in the same country, different local conditions can lead to different risk forms and severity which require the national health authorities to set up specific medical programs to prop up local health care resources in disadvantaged areas. In general, these areas have some common characteristics such as smaller population density, long distances from the main medical core area, limited transport etc. If we further incorporate any 
distinctive geographic conditions it would normally attract attention and special treatment from relevant medical institutions. Although any diseases in these areas are considered limited in scope and seriousness due to the small population, once an infection does take place it will naturally spread rapidly due to the frequent interactions between people and will probably turn into a large-scale epidemic. Therefore, most countries concentrate their efforts in providing every kind of assistance to vulnerable areas to compensate for their shortage in medical services. Yet there still will be a great diversity between each place depending on the programs and attitudes of local medical authorities and the health care institution management, and the difference of residents' awareness and alertness to disease. The resident's disease risk assessment ability to local disease is often the primary work goal in health education planning.

Taiwan occupies an area of 36,00o km2 (2/3 being mountainous regions) which includes many islands such as Penghu islands, Green island, and Liouciou island. The population is around 23 million and is mainly concentrated in several large cities on the west coast. The northern area in particular has the highest population density and prosperous economic development and is thus the principal medical core area. The southern and eastern regions are the semiperiphery regions and the distant and sparsely populated islands are the periphery areas.

From this viewpoint, this paper addresses three questions:

1. How do places with different health care resources result in different disease risk in each area (especially areas that are far away from core areas) and how do their health care systems operate?

2. What are the ideas of central health care policy makers? And what are the opinions of local health authorities to implement those ideas?

3. What awareness and understanding do local residents have about their medical environment and how have they adapted? How will the outcomes and local development embed with each other?

This paper selected Liouciou island - an island about 15 kilometers from Donggang, Pingtung County - as the study region, not only to clearly assess its local disease risk, but also to analyze the situations of local residents' adaptation process.

\section{Geographic environment and medical resources in Liouciou island}

Liouciou Island (Figure 1) is only $6.8 \mathrm{~km} 2$ and is primarily coral limestone which is dry and barren and not suitable for cultivation. It is located in a tropical climate and has one of the highest frequencies of typhoons in the region. In addition, owing to geological factors, residents sometimes have to face water shortages and, thanks to the construction of a submarine pipeline, can obtain additional water from Pingtung County. People still however put containers outdoors to collect rainwater for planting.

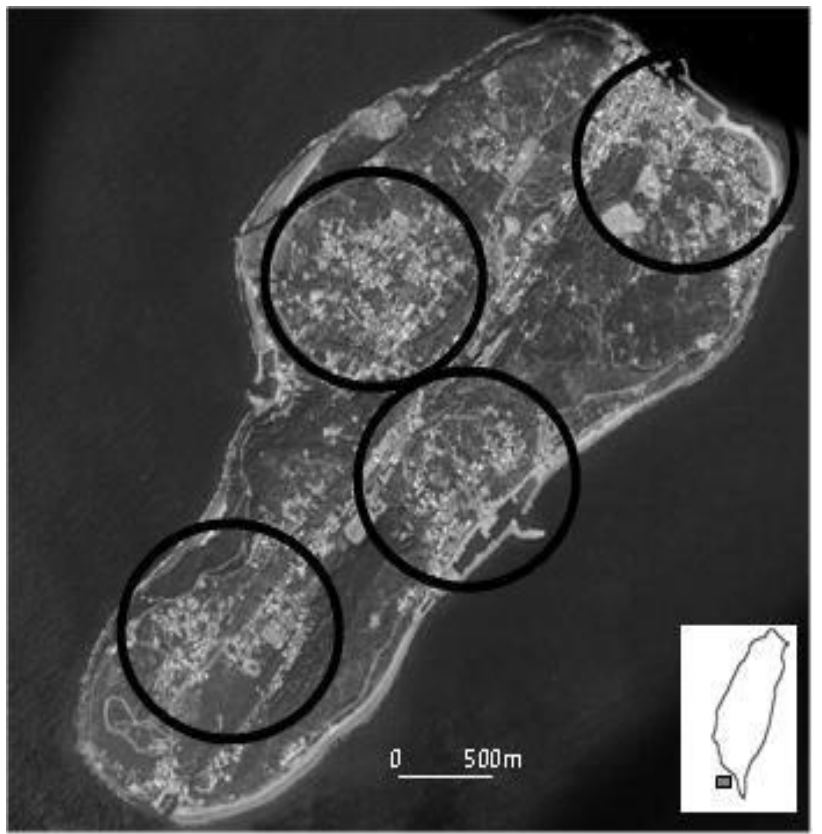

Figure 1.The location of principal 4 villages in research areas

Liouciou village has about twelve thousand people and most of them are fishermen or engaged in fisheries-related industries. Because it is abundant in migratory fish resources, many young people choose to work for offshore fishing or just move to Taiwan for work. This leaves mostly the elderly and children on the island. It should be mentioned that in their traditional culture, with its close relationship to the sea and fishing, religious belief is a central focus of their daily lives. Thus, residents regard temples as a central meeting place and they donate large parts of their savings to their own temple so there are many sumptuous and gorgeous temples around the island.

Due to the small population and limited transport, only a few private medical clinics are willing to set up in Liouciou, so the Public Health Center is the largest and most important medical institution on the island. It has set up a chronic kidney disease (CKD) dialysis center, rehabilitation centers, four private clinics and one dental clinic. The Public Health Center plays an important role on Liouciou and has many responsibilities. These include disease treatment, disease prevention education and other medical related businesses such as monitoring of environmental health, health education promotions and health checks. However, due to lack of health care staff they are not able to offer inpatient services or weekend and evening outpatient services. In order 
to strengthen the medical resources and health care of Liouciou islands, the Central Government carried out an IDS program (Integrated Delivery System) in 1996 using an entirely outsourced process, in conjunction with local medical resources, hoping to support and integrate remote islands and mountainous areas' medical services in the hope of solving the problem of inadequate medical care in those areas. And "AnTai Hospital" (in Donggang Town, Pingtung County) in IDS program was designated to support the Liouciou village general out-patient clinic, and maintain some specific services like after hours emergency, specialist clinics, maternity services, etc. In an emergency the Public Health Center provides an Ambulance boat for transfer to the mainland. The Ambulance boat is on standby at any time and, as long as patients meet the requirements, they are able to take the boat to Donggang hospitals.

\section{Purpose of the study}

According to the former questions and medical environment in Liouciou Island, there will be three purposes as following:

1. To explore the potential disease risk based on geographical and medical conditions in Liouciou village.

2. To analyze Liouciou residents' perception of disease risk under different local scale.

3. To realize the Liouciou residents' adaptation process about local disease risk.

\section{Method and framework}

Medical geographers try to integrate environmental and human factors by analyzing the evolution of occurring time and space of a disease in order to control the occurrence and prevention of disease, so the "locality" usually is the foremost basis for explaining diseases. In particular, to integrate carrier, human and medical institutions and local conditions into meta-analysis is a necessary step for disease geography research (Ouyang, 1994).

And regions can be defined as "remote regions" which are far away from medical resource centers and have high disease risk. Tsai (Tsai, et al., 2006) investigated residents' access and satisfaction to health care resources in remote areas (16o townships, Taiwan) and found that more than $40 \%$ of residents considered it inconvenient to go to hospital. Han (Han, et al., 2009) took Penghu islands as an example, showing that it's difficult to recruit professional health care personnel and maintain the trusting relationships between doctors and patients.

\section{Framework}

When it comes to local disease risk assessment, we not only view a country's health care policy and medical resources distribution, but also take the local geographic conditions into consideration (Ouyang, 1998). In fact, specific local disease risk assessment must embrace a geographical multi-dimensional scale with five levels - individual, family, community, island, and country - and the varied scales of health care institutions in this multi-dimensional standard assessment analysis - taking two-dimension data into account simultaneously (Figure 2). Accordingly, by interlocking these multi-scales items, medical care risk indicators could be addressed as follows:

1. Individual scale- age, sex, education, occupation, marriage, religion, social and economic status.

2. Family scale- economic status, family medical history, and lifestyle.

3. Community- medical facilities, medical information, and health care execution.

4. Island scale- medical facilities, medical personnel, medical policy execution, and proximity to medical resources (distance).

5. Country scale- medical policy, medical resources, health promotion, and disease prophylaxis.

This paper is based on a theoretical framework of analyzing the local disease risk assessment and adaptation processes of local medical resources and the health care situation in Liouciou Township, Pingtung County.

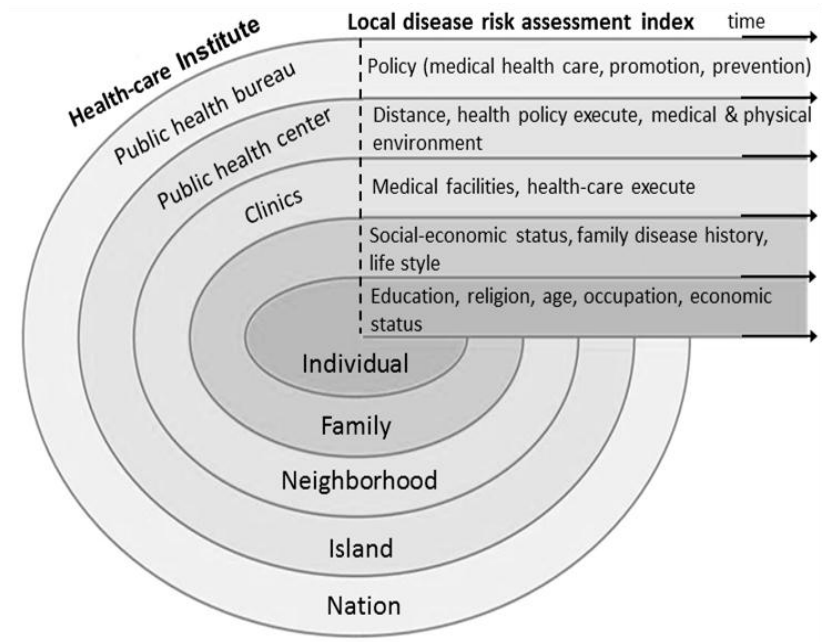

Figure 2. Research framework

\section{Methods}

The research followed semi-structured interviews with policy makers from the long-term health care division of the Department of Health $(\mathrm{DOH})$ and members of the Health Bureau of Liouciou Township, 
Pingtung County. Structured random interviews with local residents were also used for the research.

\section{Samples}

Two methods were used to gather samples. The first was from 260 questionnaires that were obtained in April 2010 that resulted in 242 valid responses (Table 1). The second sample methods were random semistructured interviews that were taken on 28-29 May 2010. These included interviews with experts from the Department of Health, the manager of the Public Health Center in Liouciou Township and local residents.

\section{Data Analysis}

The quantity data was analyzed using descriptive statistics and Chi-Square Test by SPSS 15.o. And the qualitative interview data were recorded into verbatim translation and could be collated and analyzed.

\section{Individual, Family and Neighborhood}

The Individual is the most basic unit in local disease risk assessment, and therefore personal knowledge and understanding of the local environment directly influences their attitude towards local diseases. In addition to an individual's background, which includes age, education, vocation, religion, social status, medical history, computer operating ability and dietary habits, people with diverse values and attitudes will cause differences in local disease risk assessment. Robert et al. (200o) pointed out that socio-economic status inequality, especially in disadvantaged education and income conditions, will lead to weaker health management. Moreover, different race, gender or age is often discussed and is also reflected in the local disease risk assessment. Baboret al. (2004) brought up some behavioral risk factors of basic health care assessment, such as smoking, alcoholism, physical inactivity, unhealthy diet, etc. Besides, more data related to personal medical behaviors (like the willingness of patients to accept condition tracking) should be established to strengthen the foundation of preventive health care planning.

It is essential to work out the health care habits and medical behaviors of local residents and thus local disease risk can be defined. In the case of Liouciou township, most of the residents are engaged in fishing related industries, so their living conditions and background are very similar and thus they usually encounter the same living and health issues such as dieting, drinking and disease management.

A resident (male)-

“...it's fine to go out to sea for the fresh air but the foods, wine and tobacco on the boat can easily cause high uric acid or diabetes..."

$B$ resident (female) -

"...liver disease is the most common illness of fishermen because they like staying up late drinking. And the meals on the boats are not that regular so stomach upset is common."

In fact, chronic diseases - including liver disease, kidney disease, stomach problems, gout and hypertension - are the main diseases of Liouciou Township residents, and it is related to the high proportion of the elderly in the population and the high-risks associated with fishing. The most difficult problem for local doctors to deal with is the residents' belief and faith in the temples. In other words, personal religious belief will strongly reflect on their medical behavior. One of the public health center doctors said that:

Table 1. Demographic composition of the research sample

\begin{tabular}{|c|c|c|c|c|c|}
\hline Age & Under 29 yr & $30-39 \mathrm{yr}$ & $40-49 \mathrm{yr}$ & Above 50 yr & \\
\hline $\mathrm{N}(\%)$ & $15(6.2)$ & $85(35.1)$ & $103(42.6)$ & $33(13.6)$ & \\
\hline Gender & Male & Female & & & \\
\hline $\mathrm{N}(\%)$ & $71(29.3)$ & $164(67.8)$ & & & \\
\hline Education & elementary & Junior high & Senior high & College & \\
\hline $\mathrm{N}(\%)$ & $62(25.6)$ & $98(40.5)$ & $66(27.3)$ & $11(4.5)$ & \\
\hline Vocation & Own business & Fishery & Public Service & Services & others \\
\hline $\mathrm{N}(\%)$ & $29(12.0)$ & $40(16.5)$ & $9(3.7)$ & $54(22.3)$ & $95(39.3)$ \\
\hline Residence time & Under 4 yr & $5-9 \mathrm{yr}$ & $10-20 \mathrm{yr}$ & Above $20 \mathrm{yr}$ & \\
\hline $\mathrm{N}(\%)$ & $9(3.7)$ & $21(8.7)$ & $58(24.0)$ & $136(56.2)$ & \\
\hline Family number & $1-3$ & $4-6$ & $7-10$ & Above 10 & \\
\hline $\mathrm{N}(\%)$ & $18(7.4)$ & $116(47.9)$ & $61(25.2)$ & $32(13.2)$ & \\
\hline
\end{tabular}


"Biyun Temple is the religious center in Liouciou Township and has become an important avenue for patients to "cure" their diseases. Under the guidance of Buddah they will "draw straws" from the numbered sticks container in the temple and then go to a Chinese herbal medicine pharmacy to buy the selected numbered herbal medicine. However, the herbs are not properly dispensed and the residents have limited knowledge of the herbs they take. There are no doctors for prescriptions in the Chinese herbal medicine pharmacies..."

\section{$C$ resident-}

"Our people have strong belief in God. When people get sick, it is a common way to get back to health by praying to God. You know, sometimes the 'trouble' cannot be cured by doctors, so just pray to God and believe it. It's my own idea...I prefer to go to the temple and pray...”

This tradition has been practiced for a long time so most of the people have had the experience. Although fewer young people nowadays believe in this kind of medical practice some of their parents still pray for this kind of herbal medication for them. In addition, local residents are often reluctant to talk about their unhealthy dietary and health habits (such as smoking, drinking, chewing betel nuts, etc.) even though they already know that they are likely to suffer from stomach and cerebrovascular disease (Figure 3) due to these habits. It is more obvious in the case of seeking pharmaceuticals through the temple - people don't like to talk about their personal situation but can talk about other people's behaviors easily. Moreover, most of the residents are not able to use computers to search for medical information (66.5\%). The Public Health Center has general outpatient services everyday however it doesn't get many patients. Therefore most of the patients can go to the clinics directly without the need for advance booking.

An understanding of local disease risk is commonly a part of family education and it influences residents' attitude and behavior toward disease. This can include domestic lifestyle, medical history, economic status, hygiene habits, sources of drinking water, relationships within the family and neighborhood and so on. Because they are living on a small island mutual interactions between family members, the neighborhood and relatives become an important source of medical information and disease treatment recommendations. And with the increasing numbers of foreign brides in Liouciou (accounting for $30 \%$ of the population of married women), the family attitude and approach to health-related issues has been more or less changed and adjusted.

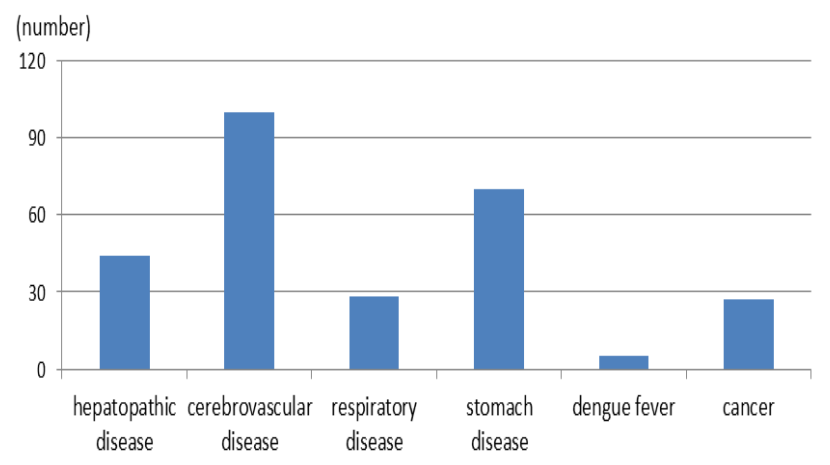

Figure 3. The most common diseases that are recognized by the residents in Liouciou township

Due to the small size of Liouciou township, residents do not feel it inconvenient with the Public Health Center and clinics being in Benfu village. The main communities are located in four main areas on the island, and most residents have lived there for many generations so that they are very familiar with each other and interact very closely. The results of the multiple choice survey regarding how the residents obtain information about various activities offered by the Public Health Center and other service information show that the highest one is the broadcast car $(57.4 \%)$, followed by friends $(44.2 \%)$ and then neighborhoods (31\%). Residents indicated that:

\footnotetext{
D resident-

“... most of the free health check activities are broadcast by the broadcast car... and sometimes the Public Health Center will send volunteers to inform us...”

E resident-

"relatives will talk ...neighbours also call me to go with them..."
}

The broadcast car is the principal channel for residents to get new information. Not only news from the government is delivered through the broadcast car but also commercial commodities and local activities. It is an efficient method of delivering information particularly when groups of residents are socializing at an arcade, in front of the temple or producing simple handcraft products in the afternoon.

\section{Township and Nation}

If people recognized their living environment, national-level health care resources and medical policies situation could reduce their disease risk. For example, firstly, the villages located on a mountain, the seashore, a lakeside, or in a desert will suffer different local endemic. Secondly, the humanities and social conditions are also an important indicator of 
local disease risk assessment, including local socioeconomic development, population and industrial structure, lifestyle, education level, transportation conditions, etc.. Ali et al. (2002) pointed out that the cholera epidemic in Bangladesh was related to supplied water and population density; Foggin et al. (2006) indicted that the health situation and disease risk factors of people in the Tibetan plateau is highly connected with their lifestyle - most of them are nomadic people who have difficultly acquiring medical information or accessing facilities which increases risks in emergencies, major illness or childbirth. Mawby et al. (1998) studied the public health risks of Lyme disease in Breckland and showed that tourists have little knowledge about the relationship between tick density, the planting pattern, humidity and temperature so it is necessary to strengthen public health education in order to avoid the high prevalence of the disease.

Making national health policies strengthen the health care works for disadvantaged areas is the problem of medical resources planning - striking a balance between medical supply and demand. The problem can be solved by financial expenditure in the majority of developed countries. In many developing countries the health policies are mostly decided by high-level government officials and often the plans are laid aside and neglected. So the understanding of residents in remote areas regarding the allocation of national health care resource or the formulation and implementation of national health policy will also affect the local disease risk assessment.

Liouciou township's medical area is subordinate to the mountainous and islands division of the Department of Health, Executive Yuan, which is a special health care unit, set up by the government for remote areas with low population density. The person in charge introduced the planning of medical care in remote areas:
“...Providing medical accessibility so the public can have basic health services, and cultivating local medical professionals to stay for service."

The greatest difficulty with planning is that:

"... It should be the economic factor. Due to the consideration of cost, hospitals cannot provide permanent medical personnel, and the doctor-patient relationship has to improve."

The secondary obstacle in the implementation is that:

"... The barriers would be cultural factors. When we started to promote some preventive health care activities to the public, the divergence of cultural understandings often diminish the effectiveness of the work and consequently we could not save on medical expenses. Furthermore, geographical conditions are also an obstacle, especially on outlying islands with frequently referred patients being transferred by the air making heavy demands on budgets."

Because of the limitations and difficulties in practicing medical work on outlying islands can the local people be made aware of the risks and what are their viewpoints of the government? This paper tries to offer greater insight into residents' understanding of these adverse conditions, and to probe the assessment situations of local medical equipment, medical technology, and service efficiency. Accordingly, the investigation divides residents' opinions of medical demand into three levels: clinics (Table 2), hospitalization services (Table 3) and emergency services (Table 4). The results showed that residents generally thought there was a serious shortage of local medical facilities. After hours emergency services, weekend and holiday services and maternity facilities being inadequate as well.

Table 2. Liouciou township resident attitude towards the local medical clinics

\begin{tabular}{|c|c|c|c|c|c|c|}
\hline Items/ N(\%) & Ample & Adequate & Normal & $\begin{array}{c}\text { Need to } \\
\text { strengthen }\end{array}$ & Deficient & $X^{2}$ \\
\hline Numbers of clinic & $\begin{array}{c}11 \\
(4.5)\end{array}$ & $\begin{array}{c}52 \\
(21.5)\end{array}$ & $\begin{array}{c}82 \\
(33.9)\end{array}$ & $75(31.0)$ & $\begin{array}{c}19 \\
(7.9)\end{array}$ & ** \\
\hline $\begin{array}{l}\text { Medical instrument of health } \\
\text { center }\end{array}$ & $\begin{array}{c}6 \\
(2.5) \\
\end{array}$ & $\begin{array}{c}61 \\
(25.2) \\
\end{array}$ & $\begin{array}{c}80 \\
(33.1) \\
\end{array}$ & $\begin{array}{c}61 \\
(25.2) \\
\end{array}$ & $\begin{array}{c}32 \\
(13.2) \\
\end{array}$ & ** \\
\hline \multirow[t]{2}{*}{ Doctors' medical skill } & $\begin{array}{c}3 \\
(1.2)\end{array}$ & $\begin{array}{c}96 \\
(39.7)\end{array}$ & $\begin{array}{c}90 \\
(37.2)\end{array}$ & $\begin{array}{c}43 \\
(17.8)\end{array}$ & $\begin{array}{c}7 \\
(2.9)\end{array}$ & ** \\
\hline & short & normal & long & & & \\
\hline Treatment time & $\begin{array}{c}31 \\
(12.8)\end{array}$ & $\begin{array}{c}197 \\
(81.4)\end{array}$ & $\begin{array}{c}13 \\
(5.4)\end{array}$ & & 694 & ** \\
\hline
\end{tabular}

$* * * \mathrm{P} \varangle .001$ 
Table 3. Liouciou township residents attitude towards the local hospitalization services

\begin{tabular}{|c|c|c|c|c|c|c|}
\hline Items/ $\mathrm{N}(\%)$ & Ample & Adequate & Normal & $\begin{array}{c}\text { Need to } \\
\text { strengthen }\end{array}$ & Deficient & $X^{2}$ \\
\hline $\begin{array}{l}\text { Medical instrument of } \\
\text { health center }\end{array}$ & $\begin{array}{c}5 \\
(2.1)\end{array}$ & $\begin{array}{c}44 \\
(18.2)\end{array}$ & $\begin{array}{c}71 \\
(29.3)\end{array}$ & $\begin{array}{c}72 \\
(29.8)\end{array}$ & $\begin{array}{c}48 \\
(19.8)\end{array}$ & $* * * *$ \\
\hline Doctors' medical skill & $\begin{array}{c}5 \\
(2.1)\end{array}$ & $\begin{array}{c}76 \\
(31.4) \\
\end{array}$ & $\begin{array}{c}107 \\
(44.2)\end{array}$ & $\begin{array}{c}45 \\
(18.6)\end{array}$ & $\begin{array}{c}7 \\
(2.9) \\
\end{array}$ & $* * *$ \\
\hline Drug supply of clinics & $\begin{array}{c}18 \\
(7.4)\end{array}$ & $\begin{array}{c}79 \\
(32.6) \\
\end{array}$ & $\begin{array}{c}100 \\
(41.3)\end{array}$ & $\begin{array}{c}37 \\
(15.3)\end{array}$ & $\begin{array}{c}6 \\
(2.5) \\
\end{array}$ & $* * *$ \\
\hline $\begin{array}{l}\text { The efficiency of sending } \\
\text { patients }\end{array}$ & $\begin{array}{c}12 \\
(5.0)\end{array}$ & $\begin{array}{c}98 \\
(40.5)\end{array}$ & $\begin{array}{c}80 \\
(33.1)\end{array}$ & $\begin{array}{c}35 \\
(14.5)\end{array}$ & $\begin{array}{c}12 \\
(5.0)\end{array}$ & $* * *$ \\
\hline Inpatient services & $\begin{array}{c}5 \\
(2.1)\end{array}$ & $\begin{array}{c}46 \\
(19.0)\end{array}$ & $\begin{array}{c}105 \\
(43.4)\end{array}$ & $\begin{array}{c}45 \\
(18.6)\end{array}$ & $\begin{array}{c}25 \\
(10.3)\end{array}$ & $* * *$ \\
\hline
\end{tabular}

$* * * \mathrm{P}<0.001$

Table 4. Liouciou township residents opinion of local medical treatment of emergency services

\begin{tabular}{|c|c|c|c|c|c|c|}
\hline Items/ $\mathrm{N}(\%)$ & Ample & Adequate & Normal & $\begin{array}{l}\text { Need to } \\
\text { strengthen }\end{array}$ & Deficient & $X^{2}$ \\
\hline $\begin{array}{l}\text { Medical instrument of health } \\
\text { center }\end{array}$ & $\begin{array}{c}3 \\
(1.2)\end{array}$ & $\begin{array}{c}48 \\
(19.8)\end{array}$ & $\begin{array}{c}98 \\
(40.5)\end{array}$ & $\begin{array}{c}68 \\
(28.1)\end{array}$ & $\begin{array}{c}23 \\
(9.5)\end{array}$ & $* * *$ \\
\hline Doctors' medical skill & $\begin{array}{c}3 \\
(1.2)\end{array}$ & $\begin{array}{c}71 \\
(29.3) \\
\end{array}$ & $\begin{array}{c}112 \\
(46.3)\end{array}$ & $\begin{array}{c}43 \\
(17.8)\end{array}$ & $\begin{array}{c}10 \\
(4.1)\end{array}$ & $* * *$ \\
\hline $\begin{array}{l}\text { The efficiency of sending } \\
\text { patients to Taiwan }\end{array}$ & $\begin{array}{c}12 \\
(5.0)\end{array}$ & $\begin{array}{r}88 \\
(36.4) \\
\end{array}$ & $\begin{array}{c}90 \\
(37.2) \\
\end{array}$ & $\begin{array}{c}42 \\
(17.4) \\
\end{array}$ & $\begin{array}{c}7 \\
(2.9)\end{array}$ & $* * *$ \\
\hline $\begin{array}{l}\text { Services at night and on } \\
\text { holidays }\end{array}$ & $\begin{array}{c}6 \\
(2.5)\end{array}$ & $\begin{array}{c}43 \\
(17.8)\end{array}$ & $\begin{array}{c}103 \\
(42.6)\end{array}$ & $\begin{array}{c}65 \\
(26.9)\end{array}$ & $\begin{array}{c}23 \\
(9.5)\end{array}$ & $* * *$ \\
\hline \multirow[t]{2}{*}{$\begin{array}{l}\text { Emergency services of } \\
\text { childbirth }\end{array}$} & $\begin{array}{c}9 \\
(3.7)\end{array}$ & $\begin{array}{c}42 \\
(17.4)\end{array}$ & $\begin{array}{c}91 \\
(37.6)\end{array}$ & $\begin{array}{c}64 \\
(26.4)\end{array}$ & $\begin{array}{c}33 \\
(13.6)\end{array}$ & $* * *$ \\
\hline & Yes & No & & & & \\
\hline $\begin{array}{l}\text { Know that Donggang services } \\
\text { Liouciou }\end{array}$ & $\begin{array}{c}201 \\
(83.1)\end{array}$ & $\begin{array}{c}37 \\
(15.3)\end{array}$ & & & & $* * *$ \\
\hline $\begin{array}{l}\text { Medical instrument and } \\
\text { doctors' services of Antai } \\
\text { hospital }\end{array}$ & $\begin{array}{c}23 \\
(9.5)\end{array}$ & $\begin{array}{c}114 \\
(47.1)\end{array}$ & $\begin{array}{c}83 \\
(34.3)\end{array}$ & $\begin{array}{c}17 \\
(7.0)\end{array}$ & & $* * *$ \\
\hline
\end{tabular}

*** $\mathrm{P}<0.001$

Residents further indicate that:

F resident-

“... The medical service has improved, for example Ambulance boats can send us to Donggang Town, but we are worried that bad weather will hinder the Ambulance boat ...... or the doctor will contact the Coast Guard Administration, Executive Yuan to dispatch a helicopter, but it is not always available..."

G resident-

“... If you become seriously ill the Health Center will send you to Donggang Town by Ambulance boat, when there is bad weather the boat cannot sail which will bring forth a lot of trouble ......, there seems no way to change this ..."
Therefore, the primary local disease risk to island residents is emergency medical treatment. Although the emergency health care system has been largely improved, they still cannot predict the weather and this worries them a lot.

In addition, Liouciou is located in a tropical area and is also a fishing port, so it usually becomes the entry point for infectious diseases from abroad. For instance, the outbreak of dengue fever in Taiwan in 1988 was first detected at Liouciou in 1981 and then spread to Taiwan in 1987. Dengue fever is the kind of epidemic that is transmitted by mosquitoes. The mosquito habitats on Liouciou were proven to be infected with dengue vector which shocked the government and health authorities. Did the Liouciou residents consider dengue fever a risk? How did the 
local Public Health Center cope with this frightening disease? An official of the Health Department pointed out that:

“... When we started to clear the source of dengue fever by overturning all the containers filled with water that were used for planting - this measure brought about intense grumbling from the residents. As a result, we gave them fish that ate mosquito larvae such as the mosquito fish, poecilia reticulate, etc. So containers with water had to be tipped over and emptied or contain breeding fish to avoid mosquito larvae growing."

After the Public Health Center took the first step in controlling the disease by overturning containers filled with water they then asked the residents to clean the ditches and surrounding environment. Since Liouciou had been infected with dengue fever since 1982 over $90 \%$ of the islands residents had been infected. After these initial preventive measures were taken dengue fever started to be under control.

Since dengue fever is very contagious and can even lead to death, how did local people recognize this disease? A middle-age woman (H resident) said:

“... at the time of the dengue fever outbreak, staff of the Public Health Center advocated emptying containers ... but now Liouciou is free of dengue fever so we don't need to worry ..."

Most of the young residents said that they did not hear about dengue fever and consider the living environment on Liouciou is much better than in the past. They also think that with the improvement to everyone's health habits there will be no more infectious diseases.

As for the medical resource problems, $50 \%$ local residents felt that it would be insufficient to meet demands, $40 \%$ people think it is sufficient and only a few made no comment. Items which residents worried about include lack of specialists, medical equipment, emergency services and especially outpatient services on public holidays. Consequently, "pharmacy" becomes the main medical resource to Liouciou residents on public holidays. Some of the larger chains of pharmacies bear the role of temporary clinics and offer medicine to patients and tourists on public holidays. The obstetrics and gynecology services are also a pressing problem. Although doctors from the IDS receiving hospital provide weekly pre-natal clinics, childbirth still have to go to Donggang hospital by ambulance boat which causes the residents great anxiety.

I resident (middle-age woman)-

"The most troublesome situation here is childbirth. Since many midwives are older and unlicensed, expectant mothers have to leave for Taiwan early before going into labor ... when the Ambulance boat is not working they must organize a boat for themselves..."

In addition to the IDS receiving-hospital the Central Government also works at enhancing and promoting local medical resources. Under the principal of "patients stay, doctor's move", it reduces related expenses from the medical referral system. Furthermore, the Health Center needs to take the responsibility of promoting health education such as free unscheduled disease screening and blood tests. Are residents aware of these activities and involved in them?

$\mathrm{J}$ resident said-

"If there is any activity the Public Health Center will make announcements from broadcast cars. We participate if we have spare time... my mom and some elders don't join us though."

In general, governmental medical supplies are unable to meet the needs of local residents even though these remote areas/islands have relatively more supporting measures that compensate for the unfair medical resources caused by distance. Among the various items that Liouciou residents expect to improve, "specialist doctors" and "specialised medical equipment" accounted for more than $50 \%$ of responses.

\section{Adaptation of local disease risks to residents}

What we are interested in is the relationships that develop with the interactions between humankind and the environment. When people encounter obstacles, physically and mentally, they will try to integrate with the surrounding environment. This process is called "adaptation". In fact, adaptation is deeply rooted in subsistence, and thus it is related to the human body and the cultural and social environment. Medical geographers explore human health problems produced from interactions of people and the environment, and especially put emphasis on the connection between human adaptation to the environment and local diseases which directly affect disease incidence. The analytic results may be positive or negative on medical indicators. For example, ignoring disease risk probably means that residents have good adaptation to the disease risk, but this outcome would be a barrier to implementing disease prevention and health promotion works. For this reason the investigation of the residents' adaptation process, could not only help realize the occurrence and therapy of local diseases, but also to use it as policy references for health-related units. 
The study of local risk adaptation has primarily focused on various types of disasters as its central theme, such as natural or man-made disasters, and their short-term or long-term risk. Also, local characteristics can be shown through the diverse responses from residents living in different regions. Yet, the local characteristic of disease risk is not easily revealed owing to the frequent interactions between regions and as a result there is little research done for local residents' disease risk adaptation. Because of the peculiar geographical and medical conditions of Liouciou township, how local residents deal with disease risk in this environment and what meaning can be put on these results are the goals of this study.

Here are some responses about the residents' attitude to the limited medical resources on the island;

\section{Resident K (young woman)-}

"...the environment and air here are good, but to tell the truth, it's not suitable for retirement life. Because medical resources are deficient and inconvenient, even if there are boats or a helicopter for emergency situations, weather problems and strict criteria for medical transport are still hard to overcome... my parents-in-law don't want to leave here, they said that they are used to the living style here..."

Resident L (old man)-

“...no matter where I live in, even in Taipei, it's inconvenient to go to clinic because I'm getting older, ... If I got seriously ill I must take the boat to the mainland... if there is bad weather I will have no choice but to wait..."

From these interviews, it is obvious that most of the residents understand the limits of local medical resources, especially the unpredictable weather, but it seems that they just do not want to change the status quo. Moreover, the elders have lived here for a long time and are settled in their hometown and thus do not care much about local disease risks.

Resident M (around seventy-year-old woman)-

"I'm very old and just waiting to go to heaven...my relatives and friends are all here so there is no need to worry..."

Resident N (temple keeper, female)-

"Life is for living...I just follow destiny, any health examination is redundant for me...and if you don't know anything about your health conditions, you don't worry..."

Those who don't care about local medical limitations are fatalists and believe in destiny, and they tend to choose remedies through their own beliefs and attitudes. In particular, the strong dependence on religion is the greatest medical risk in Liouciou. Though it is somewhat contradictory for residents, some of them still leave "life" a question for God who they most trust, especially the elders.

Resident O (middle-aged woman)-

"Medical resources here are enough for minor illnesses but not sufficient for serious disease. My mom has a bad kidney. She took lots of medicine without a prescription. Here some medicines are like health supplements which can be bought from street venders without certificate qualifications. This has caused many people to get kidney failure requiring dialysis..."

Due to the limit of medical resources and information, incorrect medical behaviors may lead to health problems. For example, there is quite a high ratio of residents who have lost their way on disease prevention (especially chronic disease such as liver and stomach troubles) - by taking too many unsuitable vitamins and believing they will help prevent them getting sick.

Resident J-

“...Living environment in Liouciou is much better now. Before people would throw out garbage on the street, but the roads are clean now and the Health Center also provides information on good sanitation... It's rare to hear about infectious disease..."

Resident H-

“... Less people are getting infectious diseases now, because we are more familiar with basic medical knowledge... and you rarely hear of dengue fever..."

Through these interviews' records, it is obvious that Liouciou's environmental quality and the resident's medical knowledge have made significant progress and improvement, especially the ability to prevent common colds and cardiovascular disease. It also potentially reduces other disease risks.

Resident P-

“...People working on the sea often have unbalanced diet, because they have less food options...so their uric acid level is usually very high. We can have blood tests regularly, but they (fishermen) have to stay on the boat throughout a year with a short break. Most of them only have blood test until the situation becomes serious..."

Resident Q-

"Actually I'm more concerned about the diseases like tuberculosis and skin diseases of our sailors... maybe we will catch tuberculosis from foreign sailors. One of my brothers-in-law has ...”

Resident R (old woman)-

“...Two of my sons-in-law passed away (only fifty/sixty years old), and both of them died of liver trouble. ... Because there was no entertainment on the boat, they just drink wine or other beverages which are bad for the liver..." 
Resident S (young man, working for administrative affairs in private clinic)-

“...sometimes young people become hepatitis B carriers from their parents. For this reason, these crew members would have health checks before they go ashore."

Most of the residents of Liouciou township are engaged in fishing (offshore fishing), especially males, they generally have a high proportion of disease risk since their way of life is influenced by their working environment. Only those residents or crew members with high awareness of their own risk, who actively monitor their own health can have a better outcome. If they don't their outcome is bleak.

Resident Ts (some middle-age men gathering in front of the temple) -

“...it's inconvenient that the Health Center isn't available at night and Medicare only offers medicine (by prescription) for three months while we need to go to sea for more than half an year... the Ambulance boat is stopped by high seas, and the procedures to apply for helicopter transport is very complicated..."

In general, most of the elders are satisfied with their life in Liouciou and have developed their own distinct medical philosophy. During the interviews, the only thing they worry about is the unsettled weather that will cause the Ambulance boat to stop sailing. It seems that they accept all the shortcomings and give their fate over to God without trying to make changes to their lives. Compared with the elders, young people are more positive and are more likely to check medical resources in particular doctors' competence and the medical facilities of the Public Health Center. Young women often make complaints about childbirth problems.

\section{Conclusion}

Different living environments lead to diverse disease risks, some of these disease risks are related to the local geographical environment, and some of them are related to medical institutions and policy makers. The residents understanding of these conditions, assessment of diseases and medical behaviors will also influence their understanding, attitude, and adaptation to disease. The process is involved with various ranges and scales, including individual, family, community, island (township), and country. Each scale has its medical care system and thus constructs distinct local characteristics.

Liouciou township is an island, which is located at the south-west side of Donggang Town, Pingtung County. On one hand, due to its particular natural environment and industrial structure - a tropical coral island which is distant from Taiwan, with a small population whose main industry is fishing Liouciou has its distinctive disease risks. For example, boats and crew members from outside may transmit dengue vector, malaria or tuberculosis. However, a large proportion of local residents are not that worried about these risks. On the other hand, some residents' medical behaviors are strongly affected by local culture, especially religion. They will seek "pharmaceutical sticks" from the temple and go directly to a Chinese herbal medicine pharmacy to buy those herbal medicines. The herbs are not properly prescribed and may produce a worse outcome. It is the most worrisome problem for the local Health Center and doctor.

This paper explores residents' perception and assessment of disease risks and collates various adaptation methods into several forms under different scales and conditions. Firstly, most residents rely on local medical resources, so they will worry whether the Ambulance boat is available or not when they have severe diseases, emergencies or childbirth problems. Secondly, different age groups have different perception and adaptation toward local medical resources. Many young people are usually dissatisfied with medical facilities and doctors' skills. Most elders believe in destiny or just give their fates over to God and do not care about medical resources very much. Last but not the least, residents engaged in fishing, notably offshore fishing, always work and stay on the boat for a long time and have no way to have long-term and regular chronic illness followups.

The fact of the matter is that Liouciou's medical environmental resource and quality, consisting of medical facilities and corresponding institution, and resident's medical knowledge and capacity, have greatly improved. As residents are accustomed to a relaxed style of living, they just hear from broadcast cars and interact with the neighborhood to get information as the basis of their medical and treatment knowledge. Though they know that some local disease risks are difficult to change, they are able to live with their own belief.

\section{References}

Ali, M, Emch, M, Donnay, JP, Yunus, M \& Sack, RB 2002, 'Identifying environmental risk factors for endemic cholera: a raster GIS approach', Health E Place 8, pp. 201210.

Babor, TF, Sciamanna, CN \& Pronk, NP, 2004, 'Assessing Multiple Risk Behaviors in Primary Care Screening Issues and Related Concepts', American Journal of Preventive Medicine 27 (2S), pp. 42-53.

Chen, CJ 1999, Epidemiology: principle and Methods, Linking publisher, Taipei. 
Foggin, PM, Torrance, ME, Dorje, D, Xuri, W, Foggin, JM \& Torrance, J 2006, 'Assessment of the health status and tisk factors of Kham Tibetan pastoralists in the alpine grasslands of the Tibetan plateau', Social Science $\mathcal{E}$ Medicine 63, pp. 2512-2532.

Han, TC \& Lin FY 2009, 'Identify remote district hospital Improvement point', Service Industry and Marketing Symposium Thesis Collection, pp. 824-838.

Lin, YC \& Wang XZ 2002, 'Health risk assessment of health promotion', The University Physical Education \& Sports 63, pp. 159-164.

Mawby, TV \& Lovett, AA 1998, 'The public health risks of Lyme Disease in Breckland, U.K.: an investigation of environmental and social factors', Social Science $\mathcal{E}$ Medicine 46 (6), pp. 719-727.

Meade, MS \& Earickson, RJ 200o, Medical Geography, Second Edition. The Guilford Press, New York, London.

Meade, MS 1977, 'Medical geography as human ecology: the dimension of population movement', The Geographical Review 67 (4), pp. 379-393.
O'Connell, E \& Hurley, F 2009, 'A review of the strengths and weaknesses of quantitative methods used in health impact assessment', Public Health 123, pp. 306-310.

Ouyang, CL 1994, 'Disease geography research -a case study of Dengue Fever in Taiwan' Ph.D. dissertation, Department of Geography, National Taiwan Normal University.

Ouyang, CL 1998, 'Geomedical health care system: The study of the central Taiwan in 1981-1998', Geographical Research 29, 33-62.

Robert, SA \& House, JS 2000, Socioeconomic inequalities in health: Integrating individual-, community-, and societallevel theory and research, the handbook of social studies in health and medicine, SAGE Publications: 115-135, Condon Thousand Oaks, New Delhi.

Tsai, W. C., P. T. Kung, C. L. Yaung, Y. H. Li, S. C. Lin, 2006. Accessibility to and satisfaction with healthcare by rural area residents. Taiwan Journal of Public Health 25, pp. 394-404. 